\title{
OPTIMIZATION OF BUILDING FAÇADE TO CONTROL DAYLIGHT EXCESSIVENESS AND VIEW TO OUTSIDE
}

\author{
NADIRI P. ${ }^{a}$, MAHDAVINEJAD M. ${ }^{b, ~ *}$, PILECHIHA P. ${ }^{b}$ \\ ${ }^{a}$ Pars University, Department of Architecture, Tehran, Iran, e-mail: parisa.nadiri.edu01 @ gmail.com \\ b Tarbiat Modares University, Department of Architecture, Tehran, Iran, e-mails: * mahdavinejad@modares.ac.ir, \\ p.pilechiha@modares.ac.ir
}

Received: 21.06.2019 / Accepted: 06.09.2019/ Revised: 10.10.2019 / Available online: 10.12.2019

DOI: 10.2478/jaes-2019-0022

KEY WORDS: Daylight, ASE, View to outside, Shading, Optimization.

\begin{abstract}
:
Windows and shading devices play a significant role in designing building facades to control the rate of the received daylight and improve visual comfort. This study is aimed to provide an optimization basis for building's façade considering two variables of Annual Sun Exposure (ASE (1000/250h)) and the view to outside of an office. In this research, the effect of various parameters of shading louvers to the south was investigated in Tehran, Iran. The parameters were number, depth, angle as well as thickness. In this review, Rhino/Grasshopper plug was employed for simulations; moreover, Galapagos evolutionary solver component was used to run the optimization process. This study's findings showed that it was possible to reach a view of nearly $90 \%$ of the interior spaces while the value of ASE (1000/250h) still remained in the reasonable range.
\end{abstract}

\section{INTRODUCTION}

Different states of building envelope components may lessen solar insolation and consequently, reduce the heating and cooling loads as well as improvement of daylight distribution (Rossi et al., 2012). In designing building façade, shading devices and windows are from the fundamental components. They significantly affect the visual comfort, daylight quality and view. Many studies have so far assessed the parameters affecting the design of windows and shading devices. It is expected that using daylight in buildings reduce the lighting electricity expenditure as well as having a considerable effect on the health of resident of indoor spaces (Boyce et al., 2003). In the interior environment, daylight and the possibility of outside view can improve worker performance while declining the stress level (Edwards and Torcellini, 2002). On the other hand, in case that the daylight access rate is not properly controlled, it results in increased cooling loads and discomfort glare. The use of shading devices leads to enhanced visual and thermal comfort; hence, they are one of the most important tools for controlling the amount of daylight and glare (Choi et al., 2017) and (Valitabar et al., 2018).
Direct sunlight must be cut in order to improve blind efficiency. For decreasing the cooling loads and discomfort glare, daylight must help task illuminance in order to reach decreased lighting electricity and preserve the view to outside (Chan and Tzempelikos, 2013). Out of various office buildings' blind types, roller blinds do not efficiently operate and residents usually close them without any operation (Choi et al., 2017). Venetian blinds are from the widespread shading systems mostly used in office buildings (Iwata, 2017). There are many daylight metrics considered in building envelope design. We can refer to Annual Sun Exposure (ASE (1000/250h)) as one the most common daylight metrics used for façade and daylight design (Ko et al., 2017).

In addition, another controversial characteristic of window design is the importance of view. The most important contribution of a window is its impact on eye health. Looking at computer for long time and with no break, computer-based workers usually experience eyestrain or dry eyes (Heschong at el., 2003). Through using different methods, some researchers have investigated the impact of both views to outside and daylight on the visual health. One method has been used by means of answering a number of questions by participant

\footnotetext{
* Corresponding author: Mohammadjavad Mahdavinejad, Associate Professor, Tarbiat Modares University, Department of Architecture, Tehran, Iran, e-mail: mahdavinejad@modares.ac.ir
} 
(Hellinga et al., 2014). Some studies have evaluated these metrics by computer simulations (Wageh and Gadelhak, 2017), (Tzempelikos, 2008), (Sherif et al., 2016). A multifunctional building in Italy was investigated by this method (Wageh and Gadelhak, 2017). In this study, the parametric model of five types of shading devices was analyzed for daylight glare and the quality of view. In another study, the impact of Venetian blind and view tilt angle's different geometries were examined (Tzempelikos, 2008).

The analysis in this research showed that the outside view rate is dependent on the blind geometry and rotation angle that influence the reflectance and transmittance of the window-blind system (Tzempelikos, 2008). In designing transparent building surfaces, in addition to the natural light, considering the view is an important factor. Since different parameters have been employed in designing process, in this investigation, it is tried to evaluate these two indices by designing a simple building surface for an office room. Various parameters are selected based on the previous investigations to evaluate the two factors, annual sun exposer (ASE) and view, which have been ignored. The variations which are effective in designing the shading louvers. The fundamental goal of the current study is simultaneously controlling the volume of daylight and the level of view to provide a proper visual quality for residents in interior spaces. The main challenge of this study is to find a solution to apply venetian blinds so that the daylight volume and the view level can be properly provided for interior spaces. Accordingly, Venetian blinds are utilized to control the volume of daylight and to prevent glare, whereas, they limit view to outside. The ASE index is selected to measure the amount of annual daylight. Driven by LEED V4, this index is introduced as one of the factors evaluating glare. In this investigation, the different parameters of shading louvers were optimized to control the ASE and the level of view.

\section{DEFINITION OF KEY TERMS}

\subsection{Annual Sun Exposure}

A high level of illuminance is one of the glare predictors .ASE is one of the three indices, which are variations of illuminancebased glare prediction indices (Ko et al., 2017). ASE $(1000 / 250 \mathrm{~h})$ calculates the floor area percentage where the illuminance level gets $1000 \mathrm{~lx}$ for at least $250 \mathrm{~h}$ over the hours the office is occupied from 8:00 am to 6:00 pm (IESNA, 2012). Moreover, this is a location-based metric. It uses the real weather data of the examined location. Hence, it considers the dynamics of climatic changes in a certain location in an entire year, not the sky conditions at a certain time (Sherif et al., 2016).

ASE is adapted as glare metrics in the daylight credit in LEED v4. The ASE calculation grids should not exceed 0.60 square meters and layout across the usually occupied area at a work plane height of $0.76 \mathrm{~m}$ above the finished floor (unless another height is defined) (https://www.usgbc.org/resources/leed-v4building-and-construction-current-version).

\subsection{View to Outside}

Recently, the term "effective outside view" has been suggested to quantify the relationship with the outdoors (in terms of the view level and view quality) for the completely applied shading case (Konstantzos and Tzempelikos, 2017). This term is intended to certify the findings that the view to the outside is a good advantage of a window. In spaces where a movable shading device is used for glare control, perforated roller shades or horizontal venetian blinds with the slats set in horizontal position may provide a view to the outside.

\section{RESEARCH METHODS}

\subsection{Simulation Model}

In this study, an office room located in the hot-arid climate of Tehran, the simulated case was oriented to the south; accordingly, we expect to have the maximum sun exposure. Driven by the IEA task 27 reference office, the office room has a rectangular shape with the dimensions of $\mathrm{L} 5.40 \mathrm{~m}, \mathrm{~W} 3.50 \mathrm{~m}$, with a ceiling height of $2.70 \mathrm{~m}$ (Mangkuto et al., 2016)- (van Dijk, 2002). The Reflectance value of the ceiling, wall and the floor respectively were $0.85 \%, 0.6 \%$ and $0.2 \%$.

The $\mathrm{WWR}^{1}$ is $35 \%$ according to (Mahdavinejad et al., 2012) recommendation; a double clear window model is applied, as well. Metal is very influential in providing the visual comfort of indoor spaces (Tabadkani et al., 2018). Accordingly, in this research, the louver material is considered metal.

The workplace area is divided into grids with the size of 0.25 square meters and the working plane is considered $0.80 \mathrm{~m}$ above the ground. While the parameters of the window were kept constant, some parameters of shading including number, depth, thickness and angle were variable, as shown in (Table 1). The space is occupied from 8:00 am to 6:00 pm.

Table 1. Margin The Shading parameters indicate the device type

\begin{tabular}{|c|c|}
\hline Shading Number & Range(1-10) \\
\hline Shading Depth & $\begin{array}{l}\text { Range }(0.05-0.55) \mathrm{m}-\text { with } \\
\text { an interval of } 0.1 \mathrm{~m}\end{array}$ \\
\hline Shading Thickness & $\begin{array}{l}(0.005) \text { m,range }(0.01-0.05) \\
m-\text { with an interval of } \\
0.01 \mathrm{~m}\end{array}$ \\
\hline Shading Angle & $\begin{array}{l}\text { Range }(0-50){ }^{\circ} \text { - with step } \\
\text { of } 10^{\circ}\end{array}$ \\
\hline
\end{tabular}

\footnotetext{
${ }^{1}$ Window-to-wall ratio
} 


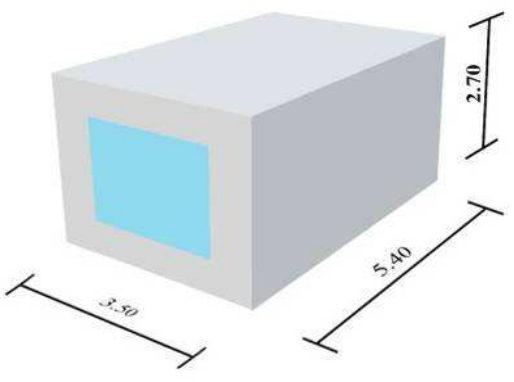

(a)

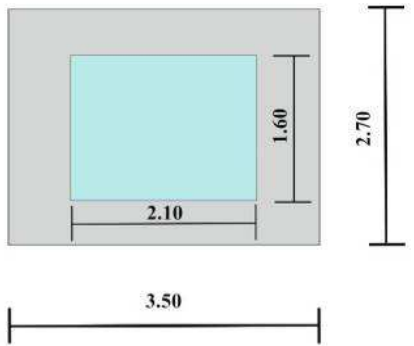

(b)

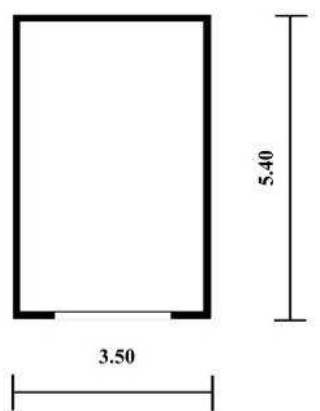

(c)

Figure 1. (a) 3D model, (b) elevation view, and (c) plan view of the simulated space

\subsection{Simulation Parameters and Procedure}

As shown in (Fig. 1), the whole configurations were measured according to Grasshopper for Rhinoceros. Grasshopper is a powerful plugin to design a form and build generative algorithms. A node-based editor is the main interface for an algorithm in Grasshopper in which data are processed via connecting wires.

A 3D parametric model was generated by Grasshopper plugin for Rhinoceros and Ladybug and Honeybee for-Rhino was used that connected Grasshopper 3D to "Radiance" and "DaySim" for daylight and lighting simulation (https://www.food4rhino.com/app/ladybug-tools).

Furthermore, optimization process was done by the "Galapagos" plugin evolutionary solver. The algorithm was created for following certain procedures in which inputs and outputs were considered. Four main variables for louver shading were defined as inputs: depth, number, thickness, and angle. In addition, the ASE (1000/250h) and the view to outside were defined as outputs for the optimization process. The whole research process is summarized in (Fig. 2). The office room was investigated in three stages. As illustrated in (Fig. 2), in the first stage, both constant and variable parameters were defined for the 3D model by Grasshopper. Stage 2 focused on measuring external view and assessing Annual Sun Exposure. In the stage 3, based on the model parameters, i.e. ASE and view, the annual simulations were carried out by evolutionary algorithms of Galapagos. A total of 1747 evaluations were made yearly and the results of simulation were collected by Excel software. Finally, we presented them in various forms.

\subsection{View Analysis}

We used the component of Ladybug-view analysis for assessing the visibility of input-geometry from main viewing points such as the type of view and size of grid shown in (Fig. 3). Horizontal $60^{\circ}$ cone of vision was considered as the view type to study views from interior spaces to the outside. The view type was selected based on the guideline of Ladybug-view analysis (http://www.grasshopper3d.com/group/ladybug ).

This view type is the percentage of the 360 horizontal view bands bounden on top and bottom by a $30^{\circ}$ offset from the horizontal human cone of vision. The grid size represents the average of a grid cell for visibility on the test-geometry.

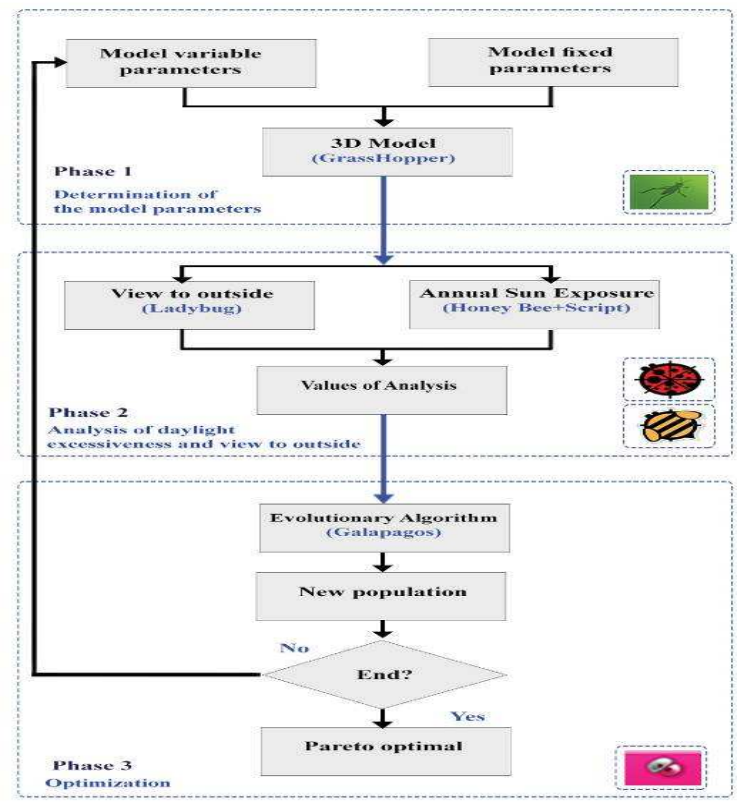

Figure 2. Workflow of the proposed algorithm

In this model, the value of grid size was considered $0.25 \mathrm{~m}$. Moreover, the level of view with the height of $1.20 \mathrm{~m}$ was used as a reference plane on which the value of view was simulated. Accordingly, at 70 points, view was analyzed in the examined office room.

Finally, view analysis results represented by component of threshold selector of Ladybug-mesh. It shows that part of a collared mesh meeting a certain conditional statement and visualizing the value of the view percentage of the input geometry.

\subsection{Annual Sun Exposure Analysis}

Ladybug-sunlight hour's analysis' component was used in order to assess the daylight metric through Ladybug plugin. This component measures the number of hours when direct sunlight is received by input geometry that uses sun vectors of the component of sun path. Similar to view analysis, the results of 
this component were visualized by component of threshold selector of Ladybug-mesh .In this model, the working plane with the height of $0.80 \mathrm{~m}$ was considered as a reference plane where $\operatorname{ASE}(1000 / 250 \mathrm{~h})$ was simulated and the grid size was considered $0.25 \mathrm{~m}$. Accordingly, at 70 points ASE(1000/250h) were analyzed in the examined office room. (Fig. 4) illustrates the position of the analysis points for both ASE (1000/250h) and view. (Fig. 5) shows one of the visualizations for ASE (1000/250h) metrics in the input geometry.

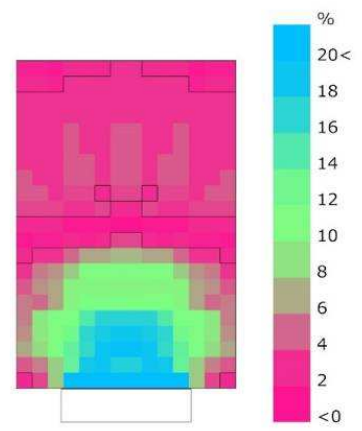

Figure 3. The simulation model for analysis of view to the outside (Horizontal $60^{\circ}$ cone of vision analysis created by Ladybug component)

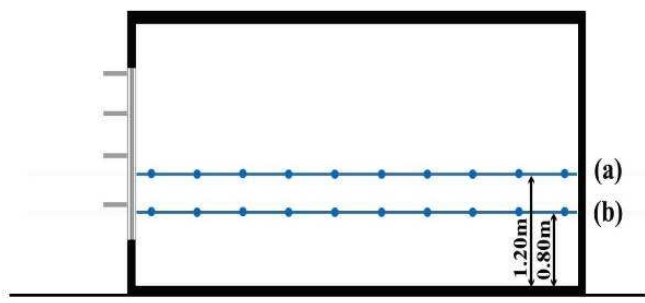

Figure 4. (a) grid-based view level, and (b) a grid-based working plane

\subsection{Optimization Process}

To conduct the optimization process, Galapagos evolutionary solver component was used as illustrated in (Table 2). Biological mutation, selection and inheritance principles are applied by the evolutionary algorithms, virtually populating with a number of individuals forming generations. After creation of the new generations, the algorithms save the best ones according to the defined fitness function. This process is continued until their offspring becomes closer to the peak values (Rutten, 2013) and (Lavin and Fiorito, 2017). It is necessary that to define genome as output and fitness as input. An output can be defined in the genome, the final subtraction value of the view and ASE $(1000 / 250 \mathrm{~h})$ was attributed to the genome in Galapagos component. As previously explained, four variables were defined as inputs for louver shading. Finally, we considered the objective functions to be maximized in Galapagos evolutionary solver component to find optimal modes.

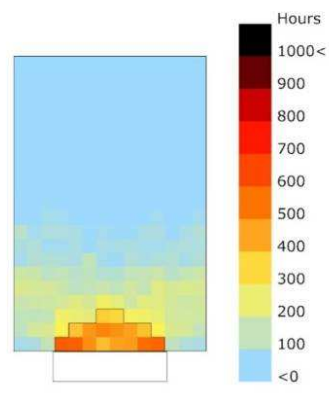

Figure 5. The simulation model for analyzing annual sun exposure created by Ladybug component

Table 2. Galapagos evolutionary solver parameters

\begin{tabular}{|l|l|}
\hline Optimizer & Galapagos \\
\hline Optimization Attribute & Genetic Algorithm \\
\hline Genome & $\begin{array}{l}\text { Angle, Thickness, Number, } \\
\text { Width }\end{array}$ \\
\hline Fitness & Maximizing |View-ASE \\
\hline
\end{tabular}

\section{RESULTS}

In this paper, different parameters of shading were studied for designing building façade considering Annual Sun Exposure (ASE (1000/250h)) and view to the outside which requires care to improve quality of the indoor environment. The model simulated here was a generic south-directed office room in Tehran, Iran. Therefore, Daylight was simulated using Tehran's annual weather data. The best optimal solutions were obtained through balancing AES (1000/250h) and view, while the algorithmic procedure was aimed to minimize the ASE (1000/250h) percentage for avoiding the direct sun exposure of the office while maximizing the view value. According to the four main variables, 1747 assessments were made. In the initial assessment for outside view index, the numerical range of (599) \% was obtained; and for ASE (1000/250h) index, the numerical range of (0-35) \% was obtained. After that, it was also considered that desirable rate of ASE (1000/250h) is less than $10 \%$ in the interior spaces. Hence, ASE (1000/250h) values greater than $10 \%$ were deleted and totally 716 states were assessed. Consequently, in this case, the range of (5-89) \% for view index, and the range of $(0-10) \%$ for ASE (1000/250h) were respectively computed as shown in (Figs. 6 \& 7).

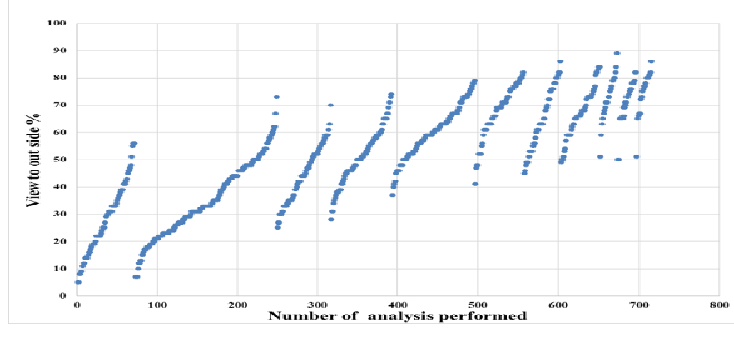

Figure 6 . The view range in the analysis process 


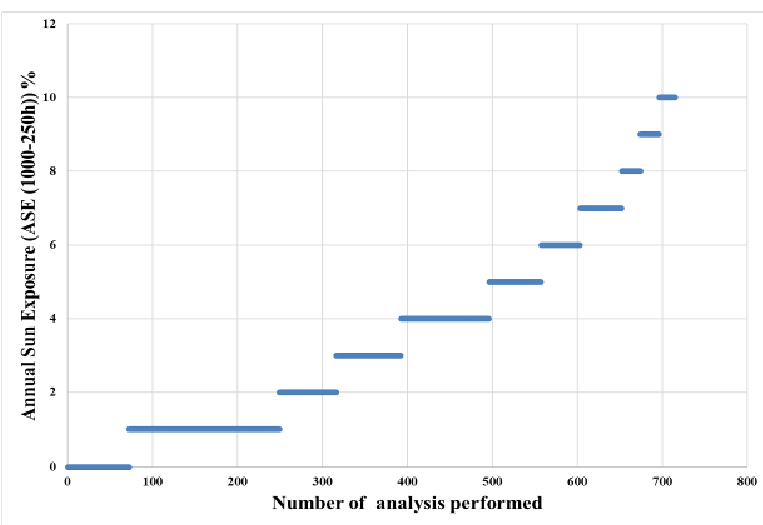

Figure 7. The Annual Sun Exposure range, ASE (1000-250h) percentage in the analysis process

According to the (Fig. 7), the values of $1 \%$ and $4 \%$ were the most frequent ones for ASE (1000/250h) index that the most percentages of their view were $73 \%$ and $79 \%$, respectively. In addition, as illustrated in (Fig. 6), through the acceptable states, $53 \%$ of the states had view values more than $50 \%$. Eleven sets of Pareto optimal solution were selected based on the results demonstrated in (Fig. 8). In the optimization process, we looked for a case that the area receiving direct daylight decreased and the possibility of view to outdoor for residents increased.

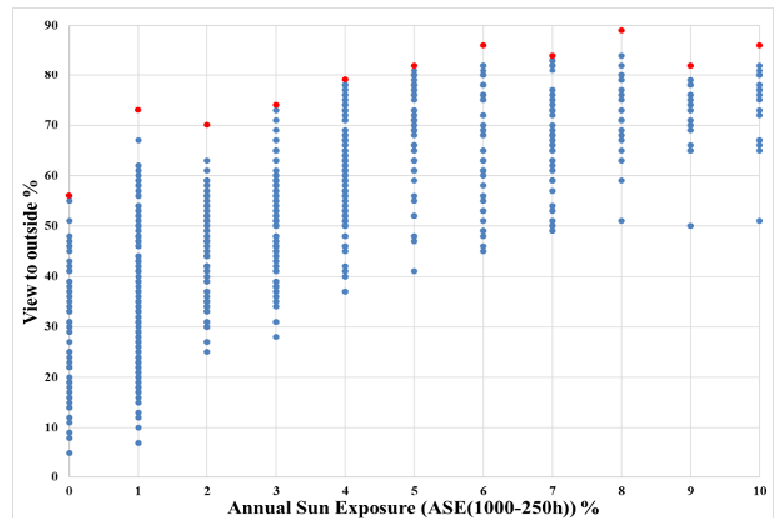

Figure 8. Illustration of outputs of genetic algorithm and relationship between view and ASE (1000-250h); red dots stand for possible optimal solutions

We found eleven optimal solutions that all of which are of Pareto frontiers. (Table 3) presents eleven alternatives generated by this method. We considered a defined range for louvers thickness $(0.005) \mathrm{m},(0.01-0.05) \mathrm{m}$ with an interval of $0.01 \mathrm{~m}$ and the defined range for louver depth was $0.05-0.55 \mathrm{~m}$ with an interval of $0.1 \mathrm{~m}$; and the louvers number was in the range of $(0$ -10). The angles of louvers were considered between $(0-50)^{\circ}$ to the horizontal axis changed with step of $10^{\circ}$. According to the results obtained in this study, louvers with low thickness had better performance; so that, among the eleven optimal solutions, ten sets had a thickness of $0.02 \mathrm{~m}$ or less. In the optimal states, there was no angle greater than $10^{\circ}$, as the number of the louvers was 5 or more. This point shows that to get the desired amount of vision in a state that the value of ASE (1000/250h) is controlled, the usage of louver with a very small angle $(0$ or $10)^{\circ}$ and the number of 5 or more can be considered as the optimal mode. The louvers depth was variable according to their number. In the cases where there were deeper louvers, the number of louvers was lower; and in the cases with a lower depth of louvers, the number of louvers was greater.

According to (Table 3), the best view value was achieved approximately $90 \%$, while a value of $8 \%$ was obtained for ASE (1000/250h). (Figs. $9 \& 10)$ present the values of view and ASE $(1000 / 250 \mathrm{~h})$ in the examined room for the optimal solution $\left(9^{\text {th }}\right.$ mode). In this case, the amount of depth, number, angle, and thickness variables were respectively $0.45 \mathrm{~m}, 5,0^{\circ}$ and $0.005 \mathrm{~m}$.

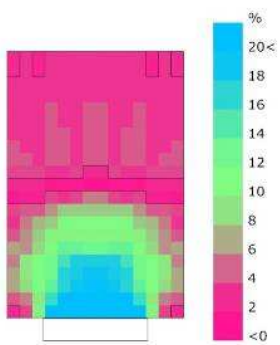

Figure 9. The view percentage in the input geometry for the best-optimized solution.

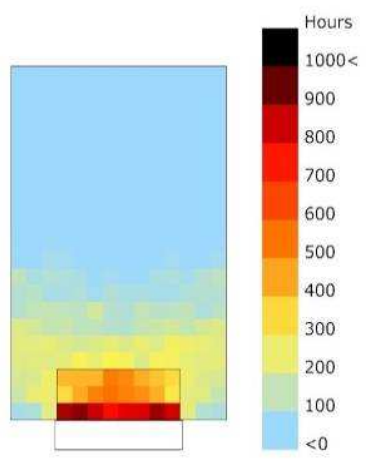

Figure 10. Representation of the Annual Sun Exposure (ASE (1000-250h)) percentage in the input geometry for the bestoptimized solution

The ASE (1000/250h) and view values in the room space for other 10 optimal solutions are respectively presented in (Figs. $11 \& 12$ ). As shown in these Figs., it is obvious that the points closer to the window received more percentage of view and ASE (1000/250h) than the farer ones. Moreover, as observed, louvers play a significant role in enhancing the visual comfort metric of ASE (1000/250h) as well as view for different cases.

Table 3. The values of the defined variables for eleven possible optimal solutions

\begin{tabular}{|c|c|c|c|c|c|c|}
\hline State & Depth(m) & Number & Angle & Thickness(m) & ASE\% & View\% \\
\hline 1 & 0.15 & 9 & 10 & 0.05 & 0 & 56 \\
\hline 2 & 0.25 & 10 & 10 & 0.005 & 1 & 73 \\
\hline 3 & 0.25 & 10 & 0 & 0.02 & 2 & 70 \\
\hline 4 & 0.35 & 10 & 0 & 0.01 & 3 & 74 \\
\hline 5 & 0.25 & 10 & 0 & 0.01 & 4 & 79 \\
\hline 6 & 0.55 & 5 & 0 & 0.01 & 5 & 82 \\
\hline 7 & 0.55 & 5 & 0 & 0.005 & 6 & 86 \\
\hline 8 & 0.35 & 5 & 10 & 0.005 & 7 & 84 \\
\hline 9 & 0.45 & 5 & 0 & 0.005 & 8 & 89 \\
\hline 10 & 0.35 & 6 & 0 & 0.02 & 9 & 82 \\
\hline 11 & 0.35 & 5 & 0 & 0.02 & 10 & 86 \\
\hline
\end{tabular}


Different figures were developed (Figs. 13 to 20) in order to illustrate the impact of each variable on ASE (1000/250h) and view. They show the values of view and ASE (1000/250h) obtained by different louver parameters for the eleven optimal cases. Generally, it is worth noting that louver's depth and number have more considerable impacts on ASE (1000/250h) and view output compared to the two other variables. (Fig. 13) illustrates the impact of the louver depth change on ASE $(1000 / 250 h)$ values in the examined room space. The minimum ASE (1000/250h) performance (0) \% was achieved in $0.15 \mathrm{~m}$ depth. The ASE $(1000 / 250 \mathrm{~h})$ values decreased with reduction of louver depth. Moreover, in the cases in which the louvers had lower depth, the louver number was greater as shown in (Figs. $13 \& 14$ ).

It could be concluded that the lower depth and the greater number of louver is, the better the ASE (1000/250h) performance will be. As an example in state 2, with 10 numbers of louvers and the depth of $0.25 \mathrm{~m}$, the value of ASE $(1000 / 250 h)$ was $1 \%$. However, the impacts of louver depth and louver number were different on view values in the space room. Fig. 15 illustrates the relationship between view and louver depth. The view values increased with raising the louver depth. Besides, in the cases where the louvers were deeper, the number of louvers was lower as shown in (Figs. $15 \& 16$ ). Therefore, the performance of louver's depth and number on view was completely different from that on ASE (1000/250h).
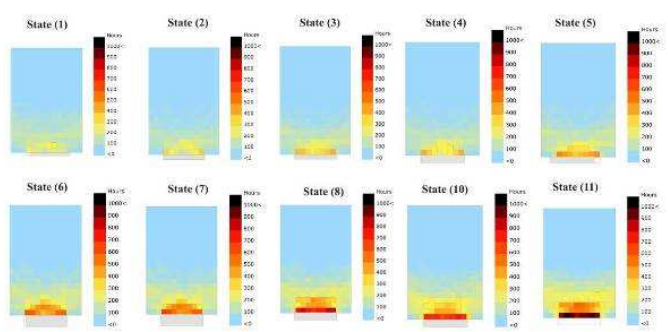

Figure 11. The Annual Sun Exposure (ASE (1000-250h)) percentage in the input geometry for 10 optimal solutions

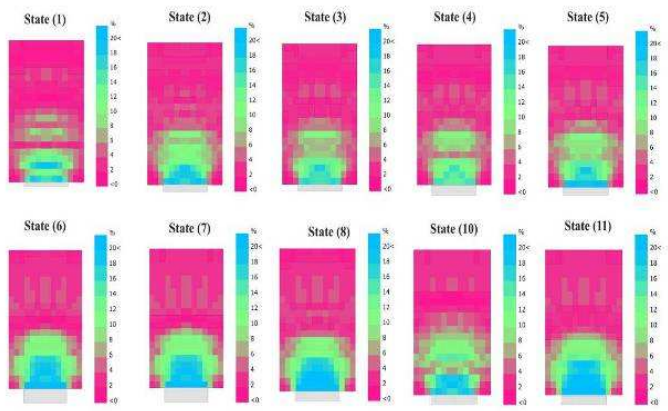

Figure 12 . The view percentage in the input geometry for 10 optimal solutions

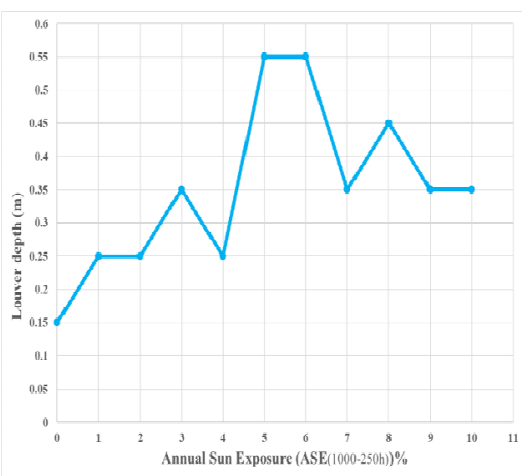

Figure 13. The impact of the louver depth change on ASE (1000-250h) values in the examined room space

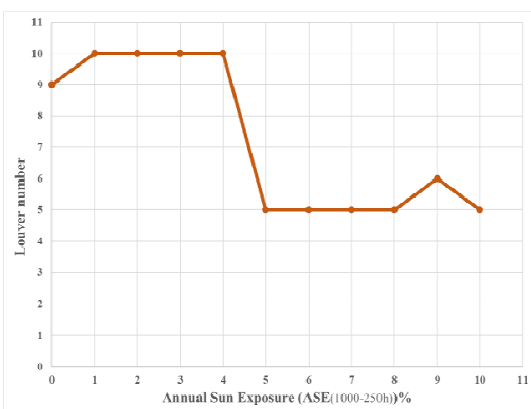

Figure 14. The impact of the louver number change on ASE (1000-250h) values in the examined room space

According to the analysis, it was found that horizontal louvers with the angle of $0^{\circ}$ obtained better results for both ASE $(1000 / 250 h)$ and exposure to the external view (Figs. 17 and 18). As previously mentioned, louver thickness of $0.02 \mathrm{~m}$ or less had better performance in both $\operatorname{ASE}(1000 / 250 \mathrm{~h})$ and view (Figs. 19 and 20).

\section{CONCLUSION}

A $\mathrm{DOA}^{2}$ has been proposed here in order to examine the possible optimal solutions for different shading parameters to achieve the goals of both ASE (1000/250h) decrease and an increased view needed by the user in the office building. The results were analyzed in order to evaluate the association between the input and outputs variable quantities. Findings indicated that if the variables are properly designed, they will receive the desired amount of both indices of ASE $(1000 / 250 h)$ and the view that are possible in indoor spaces. The result revealed that among the eleven optimal solutions, six sets had a view more than $80 \%$; while the ASE $(1000 / 250 \mathrm{~h})$ did not get over $10 \%$ of the room's area. Based on the analysis, it was found that the amount of the louver angle was approximately constant for the optimal solutions; while the depth, thickness and number of louvers were variable. It is noteworthy that the relationship between the louver depth and

\footnotetext{
${ }^{2}$ Design Optimization Approach
} 
the louver number for ASE (1000/250h) was entirely different from that for the view.

In addition to the asserted points, there are some limitations in this investigation, which will be mentioned .Given the fact that the investigation's findings are achieved only by simulation and computational optimization, and since optimization does not necessarily have any absolute result, the outputs should be evaluated in a real room. Different parameters are effective in designing building surfaces; however, only some of them are asserted.

It is simulated in office room; moreover, the user's visual comfort is evaluated and the effects of other factors are ignored. Moreover, in other kinds of building surfaces with different applications under various climatic conditions, evaluation of the pointed indices, ASE (1000/250h) and view may obtain different results. This study was a process that can be applied to other projects by simulation.

n.d.

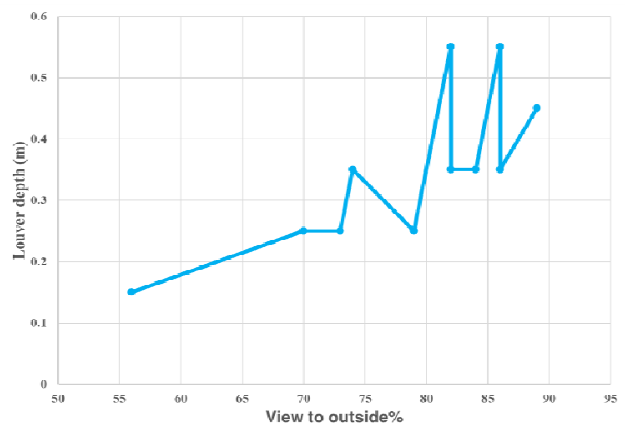

Figure 15. The impact of the louver depth change on view values in the examined room space

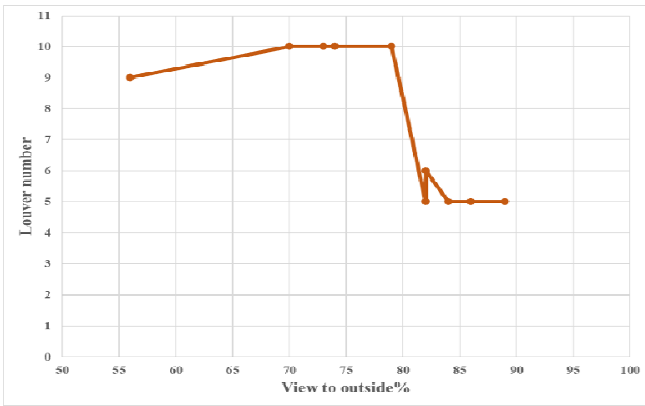

Figure 16. The impact of the louver number change on view values in the examined room space

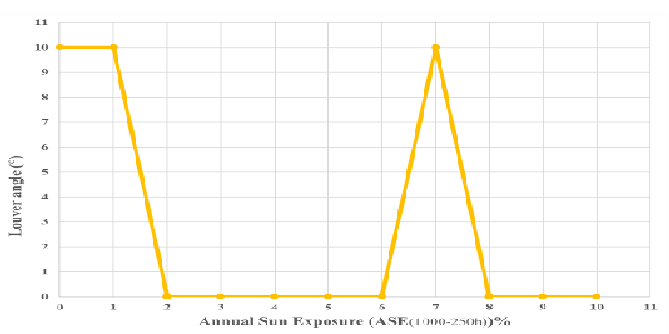

Figure 17. The impact of the louver angle change on ASE

(1000-250h) values in the examined room space

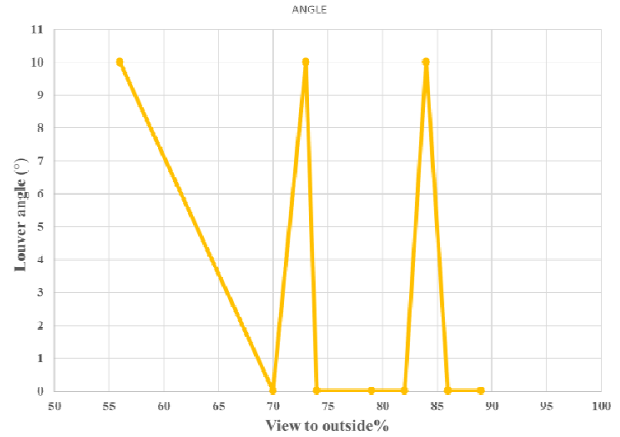

Figure 18. The impact of the louver angle change on view values in the examined room space

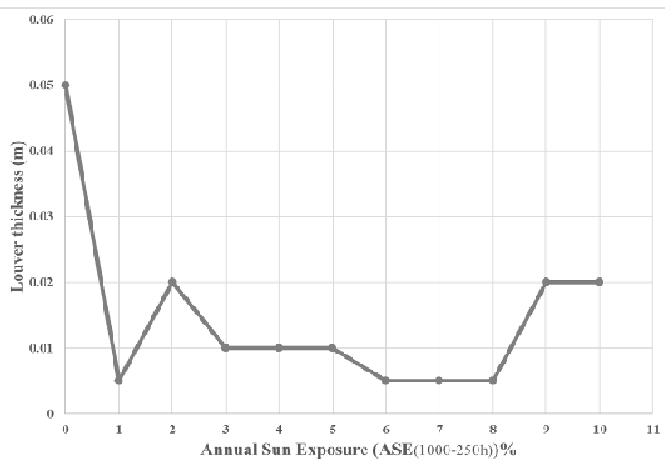

Figure 19. The impact of the louver thickness change on ASE $(1000 / 250 \mathrm{~h})$ values in the examined room space

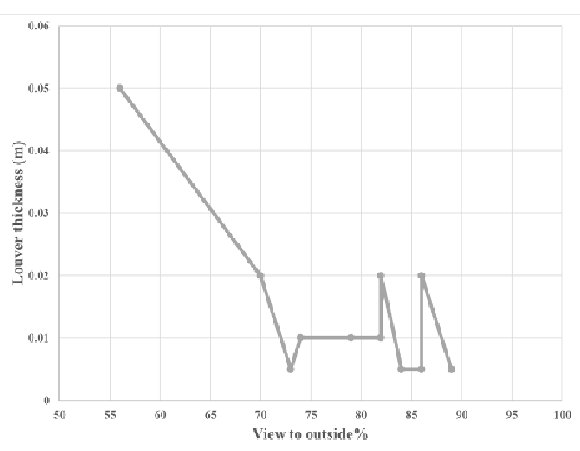

Figure 20. The impact of the louver thickness change on view values in the examined room space

\section{References:}

Boyce, P., Hunter, C., and Howlett, o. (2003). The benefits of daylight through windows. literature review, Troy, New York: Rensselaer Polytechnic Institute.

Chan, Y. C., and Tzempelikos, A. (2013). Efficient venetian blind control strategies considering daylight utilization and glare protection, Solar Energy 98, pp. 241-254. https://doi.org/10.1016/j.solener.2013.10.005.

Choi, S. J., Lee, D. S, and Jo ,J. H. (2017). Lighting and cooling energy assessment of multi-purpose control strategies for 
external movable shading devices by using shaded fraction, Energy and Buildings 150, pp. 328-338. https://doi.org/10.1016/j.enbuild.2017.06.030.

Choi, Y. C., and Tzempelikos, A. (2013). Efficient venetian blind control strategies considering daylight utilization and glare protection, Solar Energy 98, pp. 241-254. https://doi.org/10.1016/j.solener.2013.10.005.

Edwards, L., and P. Torcellini. (2002). Literature review of the effects of natural light on building occupants. Technical Report, Golden, CO.(US): National Renewable Energy Lab. https://doi.org/10.2172.

Hellinga, H., Heste, T., and Hordijk, T. (2104) .The D\&V analysis method: A method for the analysis of daylight access and view quality, Building and Environment 79, pp. 101-114. https://doi.org/10.1016/j.buildenv.2014.04.032.

Heschong, L., Higgins, C., Jenkins, N., Surles, T., and Therkelsen, R. L. (2003). Windows and offices: A study of office worker performance and the indoor environment, California Energy Commission (California Energy Commission), pp. 1-5.

IESNA, IES. LM-83-12.(2012). IES Spatial Daylight Autonomy (sDA) and Annual Sunlight Exposure (ASE). New York, NY, USA: IESNA Lighting Measurement.

Iwata, T., Taniguchi, T., and Sakuma, R. (2017). Automated blind control based on glare prevention with dimmable light in open-plan offices, Building and Environment 113, pp. 232-246. https://doi.org/10.1016/j.buildenv.2016.08.034.

Ko, W., Gail, B., Schiavon, S., and Selkowitz, S. (2017). Building envelope impact on human performance and wellbeing. experimental study on view clarity, UC Berkeley: Center for the Built Environment (CBE), University of California,. http://www.escholarship.org/uc/item/0gj8h384.

Konstantzos, I., and Tzempelikos, A. (2017). A Holistic Approach for Improving Visual Environment in Private Offices, Procedia environmental sciences 38, pp.372-380. https://doi.org/10.1016/j.proenv.2017.03.104.

Lavin, C., and Fiorito, F. (2017) Optimization of an external perforated screen for improved daylighting and thermal performance of an office space, Procedia engineering 180, pp. 571-581. https://doi.org/10.1016/j.proeng.2017.04.216.

Mahdavinejad, M., Matoor, S., Feyzmand, N., and Doroodgar, A. (2012). Horizontal distribution of illuminance with reference to window wall ratio (wwr) in office buildings in hot and dry climate, case of iran, tehran, In Applied Mechanics and $\begin{array}{llll}\text { Materials } & 110, & \text { pp. }\end{array}$ https://doi.org/10.4028/www.scientific.net/AMM.110-116.72. Mangkuto, R. A., Rohmah, M., and Asri, A. D. (2016). Design optimisation for window size, orientation, and wall reflectance with regard to various daylight metrics and lighting energy demand: A case study of buildings in the tropics, Applied energy 164, pp. 211-219. https://doi.org/10.1016/j.apenergy.2015.11.046.
Rossi, A., Nagy, Z., Schlueter, A. (2012). Adaptive distributed robotics for environmental performance, occupant comfort and architectural expression, International Journal of Architectural Computing 10, pp. 341-359. https://doi.org/10.1260/14780771.10.3.341.

Rutten, D. (2013). Galapagos: On the logic and limitations of generic solvers, Architectural Design 83(2), pp. 132-135. https://doi.org/10.1002/ad.1568.

Sherif, A., Sabry, H., Wagdy, A., Mashaly, I., and Arafa, R. (2016). Shaping the slats of hospital patient room window blinds for daylighting and external view under desert clear skies, Solar Energy 133, pp. 1-13. https://doi.org/10.1016/j.solener.2016.03.053.

Tabadkani, A., Banihashemi, S., and Hosseini, M. R. (2018). Daylighting and visual comfort of oriental sun responsive skins: A parametric analysis, In Building simulation, 11(4), pp. 663676. https://doi.org/10.1007/s12273-018-0433-0.

Tzempelikos, A. (2008). The impact of venetian blind geometry and tilt angle on view, direct light transmission and interior illuminance, Solar Energy 82(12), pp. 1172-1191. https://doi.org/10.1016/j.solener.2008.05.014.

Valitabar, M., Moghimi, M., Mahdavinejad, M., Pilechiha, P. (2018). Design Optimum Responsive Façade Based on Visual Comfort and Energy Performance, Proceedings of the 23rd CAADRIA Conference.

van Dijk, D.(2002). Thermal and solar modelling and characterisation; the role of IEA SHC Task 27. Technical report, Delft, Netherlands: TNO Building and Construction Research.

Wageh, M. A., Gadelhak, M. I. (2017). optimization of facade design for daylighting and view to outside. A case study in Lecco, Lombardy, Italy (conference paper).

Leedv4 for building design and construction .U.S. Green Building Council, January 2018. study in Lecco,Lombardy,Italy, (conference paper). https://www.usgbc.org/resources/leed-v4-building-andconstruction-current-version.

Web site: https://www.food4rhino.com/app/ladybug-tools. Web site: https://www.grasshopper3d.com/group/ladybug. 